\title{
Pathogenesis of Henoch-Schönlein purpura nephritis
}

\section{Keith K. Lau • Hitoshi Suzuki • Jan Novak • \\ Robert J. Wyatt}

Published online: 18 July 2009

(C) IPNA 2009

\section{Erratum to: Pediatr Nephrol}

DOI 10.1007/s00467/009-1230-x

Unfortunately, there is a mistake in Figure 2. The correct figure is printed below.

The online version of the original article can be found at http://dx.doi. org/10.1007/s00467/009-1230-x.

K. K. Lau $(\bowtie)$

Department of Pediatrics, McMaster University,

1200 Main Street West,

HSC 3N27, Hamilton, ON, Canada

e-mail: keithklau@gmail.com

H. Suzuki $\cdot$ J. Novak

Department of Microbiology,

University of Alabama at Birmingham,

Birmingham, AL, USA

H. Suzuki

Department of Nephrology,

Juntendo University School of Medicine,

Tokyo, Japan

R. J. Wyatt

Children's Foundation Research Center at the Le Bonheur

Children's Medical Center,

Memphis, TN, USA

R. J. Wyatt

Division of Pediatric Nephrology,

University of Tennessee Health Sciences Center,

Memphis, TN, USA

\section{HSPN pathogenesis}

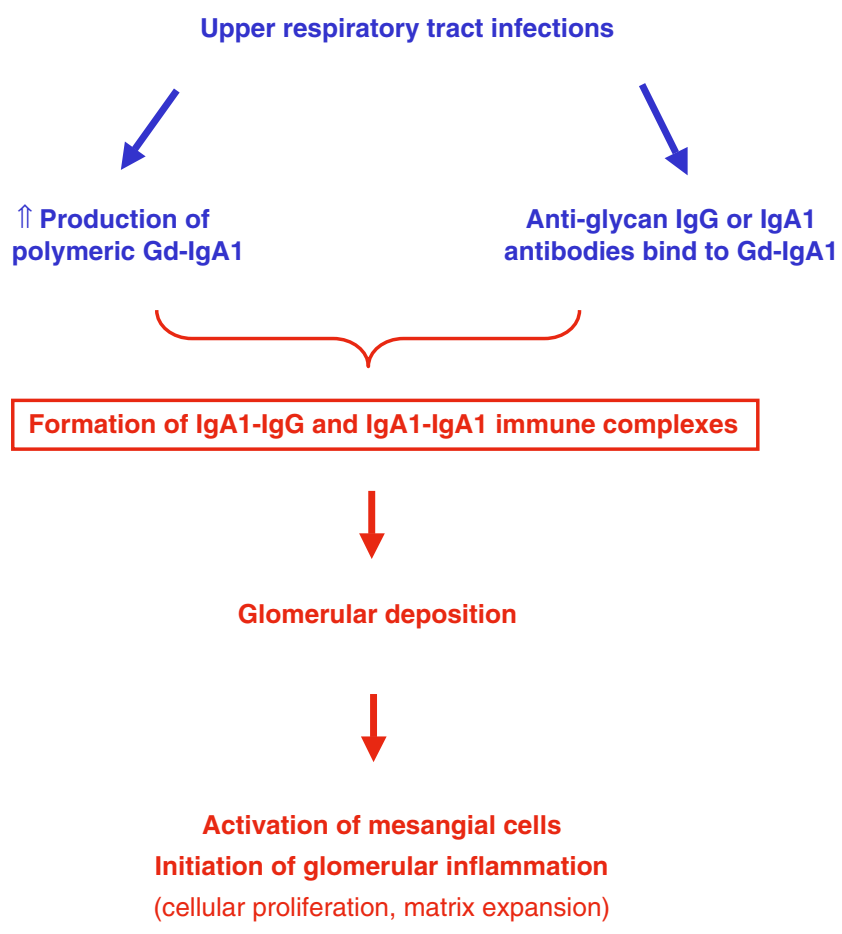

Fig. 2 Possible role of IgA1 and IgA1-containing immune complexes in the pathogenesis of HSPN 